\title{
BMJ Open Cost-utility analysis of low-intensity case management to increase contact with health services among ex-prisoners in Australia
}

\author{
Qinglu Cheng, ${ }^{1}$ Stuart A Kinner, ${ }^{2,3,4,5,6}$ Xing J Lee, ${ }^{1}$ Kathryn J Snow, ${ }^{2}$ \\ Nicholas Graves ${ }^{1}$
}

To cite: Cheng Q, Kinner SA, Lee XJ, et al. Cost-utility analysis of low-intensity case management to increase contact with health services among exprisoners in Australia. BMJ Open 2018;8:e023082. doi:10.1136/ bmjopen-2018-023082

- Prepublication history and additional material for this paper are available online. To view these files, please visit the journal online (http://dx.doi. org/10.1136/bmjopen-2018023082).

Received 21 March 2018 Revised 1 June 2018 Accepted 29 June 2018

Check for updates

(C) Author(s) (or their employer(s)) 2018. Re-use permitted under CC BY-NC. No commercial re-use. See rights and permissions. Published by BMJ.

For numbered affiliations see end of article.

Correspondence to

Qinglu Cheng;

qinglu.cheng@hdr.qut.edu.au

\section{ABSTRACT}

Objectives The economic burden of incarceration is substantial in Australia. People released from prison are at high risk of poor health and this is an important predictor of recidivism. The 'Passports Study' was a randomised controlled trial of an intervention designed to increase health service utilisation after release from prison. The aim of this study is to conduct a cost-utility analysis of this transitional programme.

Setting Australia

Design A hybrid simulation model was developed to estimate the changes to total economic costs and effectiveness expressed as quality-adjusted life-years (QALYs) from the adoption of the 'Passports' intervention compared with the control group. Model parameters were informed by linked data from Queensland Corrective Services, Medicare, Pharmaceutical Benefits Scheme, Queensland Hospital Admission Patient Data Collection, Emergency Department Information System and National Death Index. Health-related quality of life was measured using the Short-Form 8 Health Survey (SF-8). The primary outcomes were the costs and estimated QALYs associated with the intervention group and the control group. Probabilistic sensitivity analysis was conducted to test parameter uncertainties.

Results Compared with the control group where no attempt was made to encourage health service utilisation, an average participant in the intervention group incurred an extra cost of AUD 1790 and experienced slightly reduced QALYS, which indicated that the intervention was dominated in the baseline analysis. Probabilistic sensitivity analysis revealed that the transitional programme had a low probability of being cost-effective with the outcome measures selected.

Conclusion The findings of this study do not provide economic evidence to support the widespread adoption of the Passports intervention. Due to the reductionist nature of the cost-utility approach, it may be that important health-related benefits have been omitted. Another research approach using a wider range of health-related measures might generate different conclusions.

\section{INTRODUCTION}

Australia's prisoner population reached 38845 at 30 June 2016, an increase of $8 \%$
Strengths and limitations of this study

- This is the first study ever, globally, to evaluate the cost-effectiveness of a transitional programme for adults released from prison.

- We used linked data to identify recidivism, health service utilisation and mortality for a relatively large and representative cohort of ex-prisoners.

- We developed a decision-analytic model to assess the costs and quality of life associated with the transitional programme.

- This study might be limited by the health outcome measures used, as other important health-related benefits could have been omitted by the cost-utility approach.

from 30 June $2015^{1}$ and an estimated 51309 people were released from prison in Australia in $2014 .{ }^{2}$ At 30 June 2016, at least half the prisoners in all states and territories had a history of prior imprisonment. ${ }^{1}$ In Australia, $44.3 \%$ of prisoners released during 2012-2013 returned to prison within 2 years of release. ${ }^{3}$ In 2014-2015, net operating expenditure on corrective services was AUD 3.7 billion. ${ }^{3}$ The estimated average cost per prisoner per day in 2014-2015 was AUD 301. ${ }^{3}$ There likewise is a huge economic burden from criminal activity-it was estimated that the cost of crimes represented $4.1 \%$ of Australian national gross domestic product (GDP) (AUD 35.8 billion) in $2005 .{ }^{4}$

Compared with the non-offending population, prisoners have higher rates of chronic disease, mental illness, substance dependence and social disadvantage.$^{5-9}$ According to a national survey of prison entrants, ${ }^{2} 32 \%$ had at least one chronic condition; $49 \%$ had been told by a doctor that they have a mental health disorder; $67 \%$ used illicit drugs in the previous 12 months; $74 \%$ reported being current tobacco smokers and 39\% consumed 
alcohol at high risk levels in the past 12 months. Although their health might improve while in custody, where food, accommodation and low-threshold health services are provided at no cost, and where access to drugs is limited, recurrence of health impairment and a return to previous patterns of risky behaviours after release from custody are common. ${ }^{10}{ }^{11}$ Moreover, the risk of death is higher among ex-prisoners than their community peers, particularly during the first few weeks after release. ${ }^{12} \mathrm{~A}$ study in Australia estimated that the annual number of deaths each year within 4 weeks of release from prison was greater than the annual number of deaths in custody, highlighting the extreme vulnerability of ex-prisoners on return to community. ${ }^{13}$ Among the most common causes of death in ex-prisoners are drug overdose, suicide and injury $^{121415}$; however, rates of death due to communicable and non-communicable diseases are also elevated. ${ }^{16-18}$

Given that poor physical and mental health, substance abuse and social disadvantage are important predictors of recidivism, ${ }^{14}{ }^{19-21}$ improving health outcomes for ex-prisoners and supporting them in transition from custody to community is important from both a public health perspective and a criminal justice perspective. Wolitski et $a l^{22}$ demonstrated the efficacy of a sexual risk reduction project that bridges incarceration and community re-entry. Friedman $e t a l^{23}$ found that collaborative behaviour management may reduce substance use among parolees, although no difference was seen in total crime or re-arrests. The results from another study in the USA showed that personalised case management and direct monetary support may reduce recidivism in ex-prisoners by helping them navigate the re-entry process. ${ }^{24}$

Although transitional interventions are becoming widespread, there is a gap between research and policy. ${ }^{25}$ Most evaluations focus on the effectiveness of interventions, ${ }^{22-24} 2627$ but little is known about whether those interventions represent good value for money or how evidence of effectiveness can inform decision making. In today's climate of financial austerity, the great challenge for decision-makers is to allocate scarce resources among competing demands. Given the already substantial financial burden associated with incarceration, there might be limited political support for costly interventions to improve the health of ex-prisoners. Evidence that those transitional interventions make economic sense is therefore valuable in assisting policymakers who wish to invest in improving the health and well-being of this vulnerable population.

A single-blinded randomised controlled trial of a transitional intervention-the 'Passports Study'was conducted for adult ex-prisoners in Queensland, Australia. ${ }^{28}$ One thousand three hundred and twenty-five adults participated in the baseline survey within 6 weeks of expected release from custody and were randomised to the intervention group or the control group. Participants in the intervention group $(n=665)$ received a backpack containing a passport-sized booklet tailored to each participant, summarising their health status and identifying community health services relevant to their health needs. Trained workers made weekly telephone contact to the intervention group in the first 4 weeks post-release, up to a maximum of four calls, to identify health needs and encourage participants to access appropriate health services. Participants in the control arm $(n=660)$ received usual care and a letter providing a brief summary of their health status at baseline. Both groups completed follow-up interviews 1, 3 and 6 months post their first release. For those returned to custody, the follow-up interview was conducted in custody either face to face or by telephone. The intervention, which has been described in more detail elsewhere,$^{29}$ significantly increased contact with primary care services up to 6 months post-release and significantly increased contact with mental health services at the 6-month follow-up. ${ }^{30}$ The 'Passports' trial was registered with the Australian New Zealand Clinical Trials Registry (ACTRN12608000232336).

The aim of this study was to examine the cost-effectiveness of this 'Passports Study' to increase contact with health services among ex-prisoners in Australia. The cost-utility analysis reported here considered how costs and health-related outcomes changed with a decision to adopt the 'Passports' intervention. By presenting the cost per unit of health benefit gained, expressed as quality-adjusted life-years (QALYs), this work will allow decision-makers to compare this intervention with any other use of scarce resources aimed at improving health-related outcomes.

\section{METHODS}

\section{Patient and public involvement}

This study does not involve patients or public.

\section{Cost-utility model}

A hybrid simulation model was constructed to compare costs and health-related outcomes between the intervention group and the control group. The model had the structure of a Markov model but time to event was incorporated. The model ran on daily cycles and simulated participants' movements among four states within 2 years of release from prison (730 days). Figure 1 shows the structure of the model. At the beginning of simulation, all participants were released from prison and started from the 'community' state. In each day, there was a probability that participants could go back to 'prison'

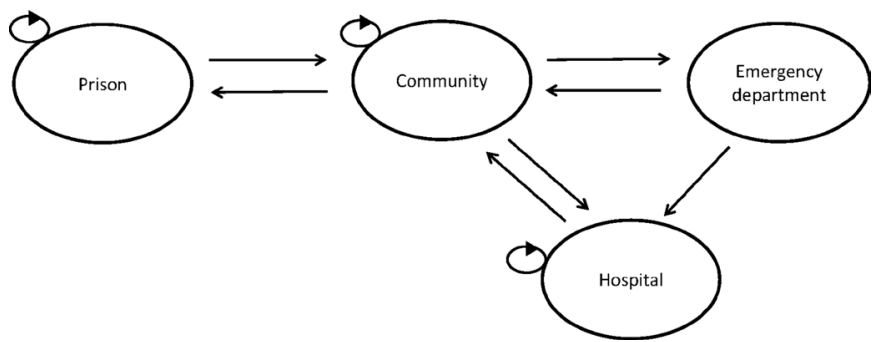

Figure 1 Simulation model structure for evaluating the costutility of 'Passport Study'. 
if they reoffended or breached supervision conditions, or visit 'emergency department (ED)', or be admitted to 'hospital', or remain in the 'community' state. If participants were reincarcerated, they would stay in 'prison' state for a period of time (time to release) before they went back to 'community'. If participants were hospitalised, they would also stay in 'hospital' state for a period of time (time to separation) before they went back to 'community'. It was assumed that participants admitted to 'ED' was either discharged or transferred to 'hospital' on the next day. Each state was assigned a cost value and a health utility weight, which were accumulated over model cycles over time.

\section{Linked data}

The data used to parametrise the simulation model were sourced from the 'Passports Study'. Participant identities were linked deterministically based on a unique prisoner number with data from Queensland Corrective Services (QCS) to identify dates of release from custody and reincarceration. The unique prisoner number was not recorded in State-based records from the Queensland Ambulance Service (QAS), Emergency Department Information System (EDIS) or Queensland Hospital Admitted Patient Data Collection (QHAPDC); or in federal records from Medicare Benefits Schedule (MBS, mainly reflecting primary care and pathology testing), Pharmaceutical Benefits Scheme (PBS) or National Death Index. Thus, linkage with these data sets was probabilistic and used all known aliases for participants. Participants' health-related quality of life (HRQoL) was assessed at each follow-up interview using the Short-Form 8 Health Survey (SF-8) that asks one question for each health domain. Linked data within 2 years of release from prison (730 days) for all individuals were used to derive model inputs.

\section{Transition probabilities and time to event}

A split Poisson process ${ }^{31}$ was applied to derive daily transition probabilities for the three transitions out of community. An average rate of transitioning out of community was first calculated by dividing the total number of transitions out of community over 2 years (730 days) by the number of individuals. The rate was then converted to a daily probability using the formula: $\mathrm{P}=1-\exp$ (-rate*time). The daily probability of a specific event (e.g., hospitalisation) was calculated by multiplying the daily probability of transitioning out of community by the proportion of transitions out of community of that event (hospitalisation). QCS data were used to inform the number of reincarcerations and the time to release from prison. Numbers of ED visits and hospitalisations were derived from EDIS and QHAPDC data, respectively. Time to separation from hospital was based on the length of stay in QHAPDC data set. The proportion of participants being discharged from ED to community or being admitted to hospital from ED were informed by participants' ED discharge destinations. The model parameters were summarised in table 1 .
Table 1 Parameters in the cost-utility model

\begin{tabular}{|c|c|c|c|}
\hline Parameters & $\begin{array}{l}\text { Baseline } \\
\text { estimate }\end{array}$ & $\begin{array}{l}\text { Standard } \\
\text { error (SE) }\end{array}$ & Distribution \\
\hline \multicolumn{4}{|c|}{ Daily probability of transitioning out of community } \\
\hline Intervention group & \multicolumn{2}{|c|}{0.0038} & \\
\hline Control group & \multicolumn{2}{|c|}{0.0037} & \\
\hline
\end{tabular}

Proportion of transitions out of community

\begin{tabular}{|c|c|c|c|}
\hline \multicolumn{4}{|l|}{ Intervention group } \\
\hline Reincarceration & 0.2929 & 0.0100 & Beta \\
\hline Hospitalisation & 0.1027 & 0.0066 & Beta \\
\hline $\begin{array}{l}\text { Emergency } \\
\text { department (ED) visit }\end{array}$ & 0.6043 & 0.0111 & Beta \\
\hline \multicolumn{4}{|l|}{ Control group } \\
\hline Reincarceration & 0.3027 & 0.0101 & Beta \\
\hline Hospitalisation & 0.0835 & 0.0060 & Beta \\
\hline ED visit & 0.6138 & 0.0112 & Beta \\
\hline \multicolumn{4}{|c|}{ Proportion of hospitalisation following ED } \\
\hline Intervention group & 0.22 & 0.0124 & Beta \\
\hline Control group & 0.21 & 0.0122 & Beta \\
\hline \multicolumn{4}{|l|}{ Time to release (days) ${ }^{*}$} \\
\hline Intervention group & 72 & 5.7618 & Gamma \\
\hline Control group & 64 & 5.6938 & Gamma \\
\hline Time to separation (days)* & 1 & 0.1958 & Gamma \\
\hline
\end{tabular}

\begin{tabular}{lccl} 
Intervention cost (one-off) & & & \\
\hline Intervention group & 90 & $\dagger$ & \\
Control group & 5 & $\dagger$ & \\
State cost (daily) & & & \\
$\quad$ Prison & 292 & $\dagger$ & Gamma \\
Hospital & 1494.37 & 27.8413 & Gamma \\
\hline ED & 538.12 & 6.2375 & Gamma \\
\hline Community & & & \\
\hline Intervention group & 4.08 & 0.2458 & Gamma \\
\hline Control group & 3.48 & 0.1936 & Gamma \\
Utility & & & \\
Community & & & \\
\hline Intervention group & 0.78 & 0.0070 & Beta \\
\hline Control group & 0.81 & 0.0059 & Beta \\
\hline Prison & & & \\
\hline Intervention group & 0.80 & 0.0279 & Beta \\
\hline Control group & 0.78 & 0.0413 & Beta \\
\hline
\end{tabular}

*Median value as baseline estimate.

†Aassumed SE was equal to the baseline estimate.

\section{Costs}

For the intervention group, the intervention costs included the cost of producing and printing a 'Health Passport', the cost of a backpack and the cost of four intervention calls. Although only a subset of participants in the intervention group received all four intervention calls when the project was carried out, we assumed that everyone received four intervention calls in the model. 
As participants in the control group received a letter that provided a brief summary of their health status when they were released from prison, the intervention cost for the control group was the cost of producing that letter.

The costs for the 'community' state were based on information from MBS, PBS and QAS data. The costs of Medicare services and medicines were recorded by MBS data set and PBS data set, respectively. The cost of ambulance attendance was based on gross expenditure per incident from the QAS Performance Report 17: 2013-2014. ${ }^{32}$ Individuals who returned to prison would incur a cost per day in custody. ${ }^{33}$ Cost per day in 'hospital' for each individual was based on the Australian refined diagnosis-related group (AR-DRG) code associated with each hospital admission and informed by AR-DRG cost and average length of stay in National Hospital Cost Data Collection Australian Public Hospitals Cost Report 2009-2010, Round $14 .{ }^{34}$ Costs associated with the 'ED' state were based on the Urgency Disposition Group (UDG) associated with each presentation. National Efficient Price and price weights for each UDG were used to calculate ED cost for each individual. ${ }^{35}$ A health system and criminal justice perspective was adopted and all costs were reported in 2013 Australian dollars. An annual inflation rate of $5.3 \%$ was derived from health expenditure index numbers between 2008 and 2013. ${ }^{36}$ Future costs were discounted at a rate of $3 \%$.

\section{SF-8 surveys and quality-adjusted life-years}

The effectiveness of the intervention was expressed in quality-adjusted life-years (QALYs) which represent both duration of life and quality of life. Information about the participants' HRQoL was collected using SF-8 Health Survey during the follow-up interviews at 1, 3 and 6 months post their first release. Answers to SF-8 questions were mapped onto preference-based Short-Form Six-Dimension (SF-6D) utility scores. ${ }^{37}$ The SF-6D utility score provides a single index to describe health state, ranging from 0 (worst health state) to 1 (full health). The SF-6D utility scores used in this study (table 1 ) were derived from the 557 participants who completed all three follow-up health surveys. It was assumed that hospitalisation and ED visits were associated with utility decrement of 0.1 and 0.05 , respectively, as there are no reported utility estimates for these transitions. By multiplying SF-6D utility score for one health state by the number of years staying in that state, QALYs were estimated for cost-utility analysis. Future QALYs were discounted at a rate of 3\%.

\section{Model evaluation}

The primary outcome was the incremental cost-effectiveness ratio (ICER), calculated as the incremental change in cost divided by the incremental change in QALY. The ICER was considered against a willingness-to-pay threshold that shows how much a decision-maker is willing to pay for one additional QALY. In Australia, there is no explicit threshold beyond which the funding body was unwilling to pay for additional life years gained, but researchers predicted low probability of recommending coverage when the threshold reached round AUD 60 000/ QALY $^{38}$ According to an international survey on cost-effectiveness thresholds, AUD $64000 / \mathrm{QALY}$ was proposed for Australia. ${ }^{39}$ If the intervention group incurred fewer costs and reported better QALYs than the control group, the intervention would be considered cost saving; if the ICER was below the willingness-to-pay threshold of AUD 64000 per QALY gained, the intervention would be considered cost-effective. If the intervention group incurred more costs but was associated with lower QALYs than the control group, then the intervention group was dominated by the control group.

To capture the uncertainty in model parameter estimates, probabilistic sensitivity analysis was conducted to allow parameters to vary probabilistically. Transition probabilities and utilities were assigned beta distributions and costs were given gamma distributions. ${ }^{40}$ For cost parameters without information on standard deviation from the data sets, it was assumed that the standard error was equal to the baseline estimate. A total of 5000 random simulations were run where a new value was drawn for each parameter from the distribution during each simulation. The results of the probabilistic sensitivity analysis were used to estimate the probability that the intervention is costeffective as the willingness-to-pay threshold varied. This analysis was presented using a cost-effectiveness plane and cost-effectiveness acceptability curve. All analyses were conducted using the statistical software $\mathrm{R}^{41}$ $\mathrm{R}$ codes and functions are available in online supplementary appendix 1 and online supplementary appendix 2 .

\section{RESULTS}

\section{Model validity and baseline analysis}

Two cohorts of individuals were simulated in the model to represent the intervention group $(n=665)$ and the control group $(n=660)$, respectively. The simulated number of events compared with actual number of events are presented in table 2. Overall, the model simulation was comparable with the observed data, with consistent underestimation of around $7 \%$ in both groups.

Total cost and QALY outcomes for the intervention group and the control group, along with incremental

Table 2 Simulated number of events compared with actual number of events using baseline estimates

\begin{tabular}{|c|c|c|c|}
\hline & Reincarceration & Hospitalisation & $\begin{array}{l}\text { Emergency } \\
\text { department visit }\end{array}$ \\
\hline \multicolumn{4}{|c|}{ Simulated number of events } \\
\hline $\begin{array}{l}\text { Intervention } \\
\text { group }\end{array}$ & 499 & 402 & 1029 \\
\hline Control group & 507 & 354 & 1028 \\
\hline \multicolumn{4}{|c|}{ Actual number of events } \\
\hline $\begin{array}{l}\text { Intervention } \\
\text { group }\end{array}$ & 539 & 433 & 1112 \\
\hline Control group & 544 & 380 & 1103 \\
\hline
\end{tabular}


Table 3 Aggregated cost (AUD) and quality-adjusted life-years (QALYs) per person for each state (2 years, 730 daily cycles)

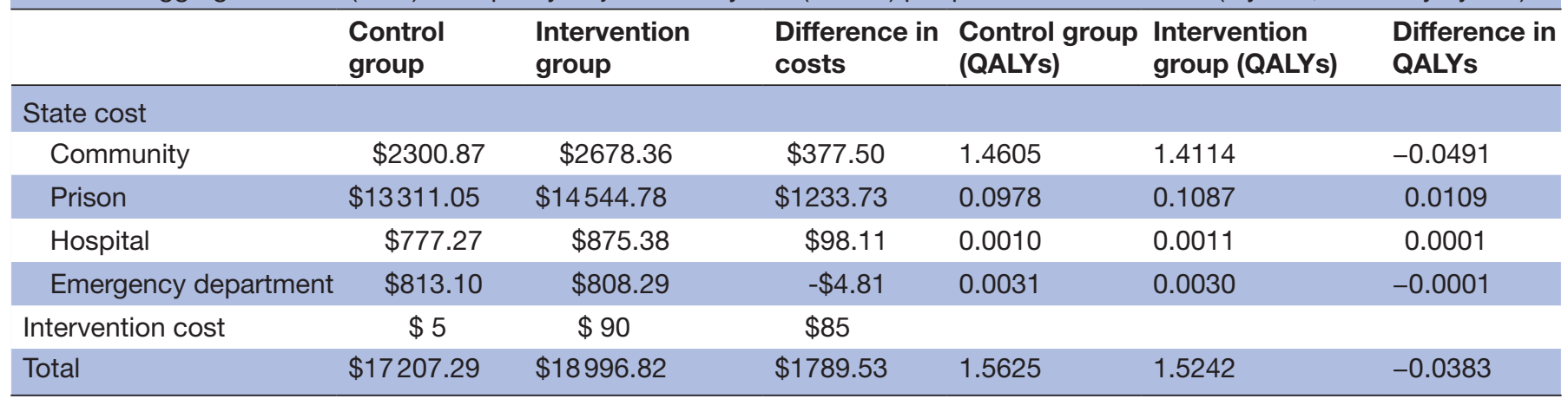

cost and incremental QALY between the two groups, are shown in table 3 . Absolute costs for each state, separately for participants in the control group and the intervention group, are also reported in table 3 . The average cost for an individual in the intervention group was higher than for those in the control group. Estimated mean QALYs for participants in the intervention group (1.52) and the control group (1.56) were similar. On this basis, it appears that the 'Passport' intervention is not cost-effective since it was associated with higher costs and no increase in QALYs.

\section{Probabilistic sensitivity analysis}

The results of 5000 simulations are presented on a cost-effectiveness plane (figure 2) where each point represents one calculation of incremental cost and incremental QALY when model parameters take random values from specified probability distributions. Points below the willingness-to-pay threshold line suggest that the intervention is cost-effective. The probability that the intervention is cost-effective at certain willingness-to-pay thresholds was derived by counting the number of times out of 5000 that a point lies below the willingness-to-pay line. For the willingness-to-pay threshold of AUD $64000 / \mathrm{QALY}$, the probability that the intervention is cost-effective is $43 \%$. The probability of being cost-effective for a range of willingness-to-pay thresholds can be summarised in a cost-effectiveness acceptability curve (as shown in figure 3). Figure 3 shows that the intervention group has a lower probability (around 33-44\%) of being cost-effective compared with the intervention, regardless of the value of willingness-to-pay threshold.

\section{DISCUSSION}

There are no published studies focusing on the cost-effectiveness of transitional programmes for prisoners. This study examined the 'Passports Study', a transitional intervention for ex-prisoners in Australia. A hybrid model was developed to simulate recidivism and health service utilisation over 2 years after study participants were released from prison. We observed higher costs in the intervention group and no increase in QALYs, suggesting that the

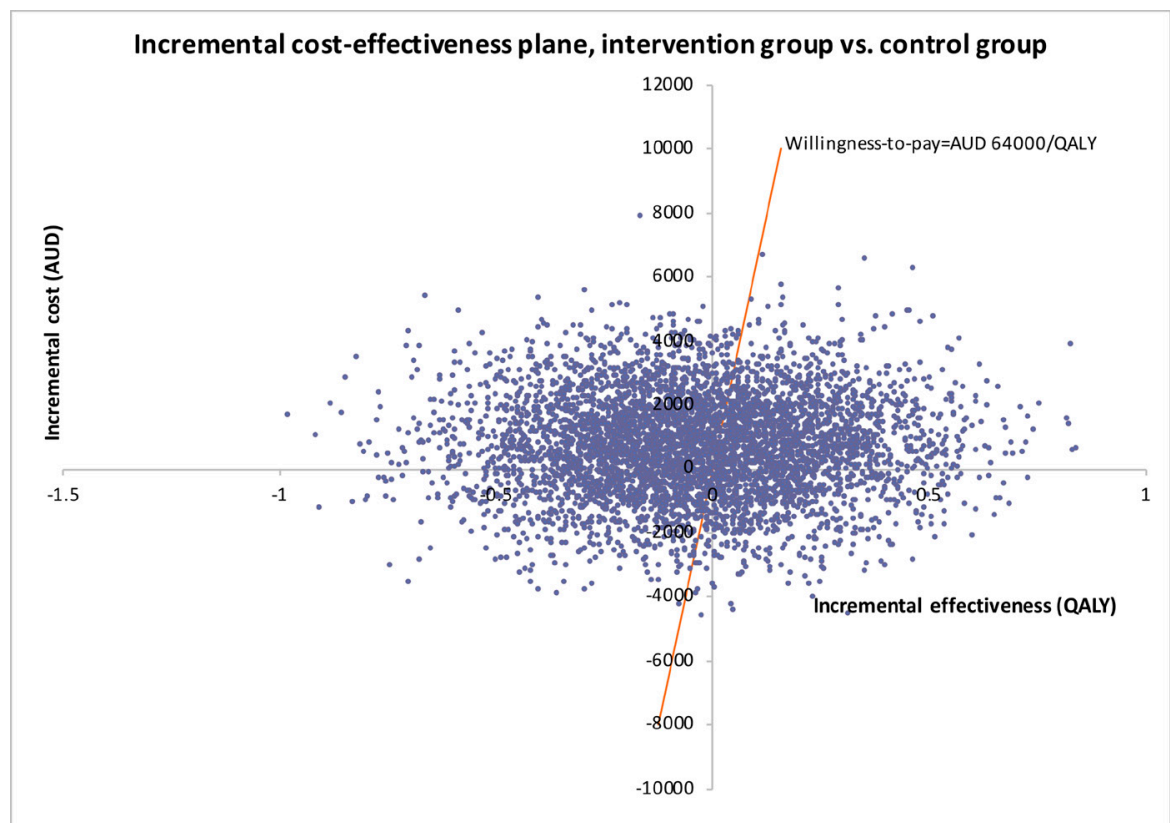

Figure 2 Cost-effectiveness plane for the intervention group over the control group. QALY, quality-adjusted life-year. 


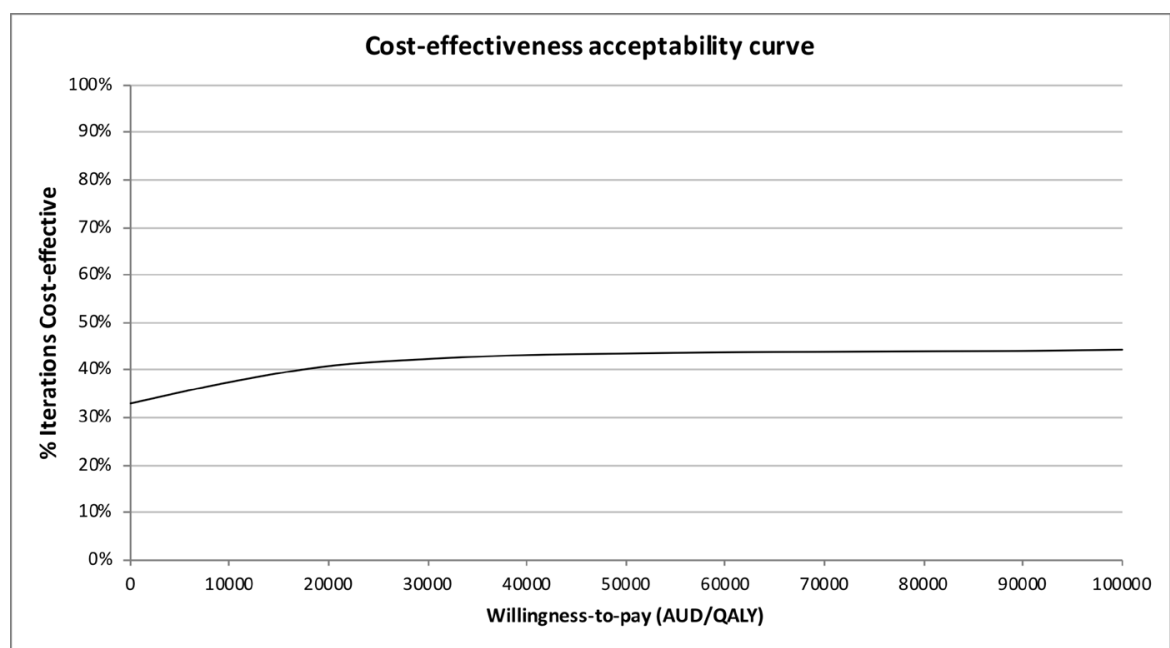

Figure 3 Cost-effectiveness acceptability curve showing the probability of the intervention being cost-effective at varying willingness-to-pay thresholds.

'Passports' intervention was not cost-effective using these outcome measures. Probabilistic sensitivity analysis was conducted to account for uncertainty in the estimates of model parameters. The results from a simulation of 5000 samples suggest that, given AUD 64 000/QALY willingness-to-pay threshold, the 'Passports' intervention had only a $43 \%$ probability of being cost-effective.

Since the proximal aim of the 'Passports Study' was to increase health service utilisation, it is not surprising that healthcare costs were increased. Kinner $e t a l^{30}$ found that those in the intervention group were more likely to report contacting with primary care at 1, 3 and 6 months post-release and more likely to report contacting mental health services at 6 months post-release. Secondary analyses revealed that early contact with primary care was associated with subsequent primary care and mental health service contact, ED presentation and hospitalisation. ${ }^{42}$ Consistent with this, in the present study, our modelling suggested a higher rate of ED presentation and hospitalisation in the intervention group. Our findings are therefore consistent with those of the original trial.

One mechanism by which the Passports intervention could have offset the increased costs from greater use of health services is by delivering better QALYs; however, our modelling based on SF-8 data did not provide evidence for this. There are a few possible reasons for this. First, it may be that although the intervention increased utilisation of health services, this did not translate into better HRQoL utility scores. Given the high prevalence of chronic health problems, health risk behaviours and entrenched social disadvantage in ex-prisoners, contact with mainstream health services may be insufficient to achieve better HRQoL for this population. Consistent with the 'inverse care law', ${ }^{43}$ there is also evidence that the quality of healthcare varies in inverse proportion to disadvantage, ${ }^{44}$ such that participants in the Passports trial may not have accessed the kind of quality care necessary to achieve measurable health improvements. One trial in the USA found that high-quality, enhanced primary care, targeted specifically at the needs of ex-prisoners, was associated with reduced ED presentation. ${ }^{45}$ Future studies of healthcare utilisation in ex-prisoners should attempt to measure both the quantity and the quality of care received.

A second reason for the observed findings may relate to our proxy for QALYs. QALYs were estimated based on SF-6D utility scores, which were in turn estimated from SF-8 survey responses. The SF-8 is a self-report measure of HRQoL, with questions assessing the perceived impact of health states on daily functioning. The Passports intervention involved making participants aware of their health-related needs (consistent with the principles of motivational interviewing ${ }^{46}$ ) and encouraging them to access healthcare to have these health needs met. As such, the intervention may have made participants more cognisant of the ways in which their HRQoL was limited, independent of any 'objective' measure of health status. It seems highly unlikely that the intervention had an inverse impact on participant's 'objective' health status. Furthermore, SF-6D utility scores were a function of SF-8 survey responses and only around $40 \%$ of participants completed each follow-up survey, with loss to follow-up associated with health risk behaviours. ${ }^{47}$ In addition, SF-8 survey has not been validated among ex-prisoner/ prisoner populations. Therefore, it is not possible to capture the full range of potential health outcomes using the SF-8/QALY approach, and in this context, given the limitations of our health measure, any conclusions must be made with caution. There are also boundaries to the value of this approach for decision making ${ }^{48}$ and another research approach, using different data collection tools, might generate different insights.

There are some further limitations with this research. First, according to the internal validation, the model underestimated the number of reincarceration, hospitalisation and ED visits in both groups by around $7 \%$. This could be caused by the way the model was set up. The model was built as a simplified representation of real-world process which captures the vital components 
of process for the evaluation, as is typical in model-based economic evaluations. ${ }^{49}$ For example, we assumed in the model that once individuals were in the 'prison' state they could not go to 'hospital' or 'ED'. If movement between 'prison' and 'hospital' / 'ED' is allowed, the 'prisonhospital-community' pathway will be enabled due to the memoryless property of model. Thus, some events were not captured and the model did not replicate observed data exactly. Moreover, the parameterisation of model inputs did not take into account individual characteristics of the participants, but represented the average behaviour of the groups instead. As a result, the total costs over 2 years could be underestimated and QALYs could be overestimated. Second, the method used to map SF-8 scores onto the SF-6D has not been validated, unlike the $\mathrm{SF} 12$ or $\mathrm{SF} 36^{50}$; this may have led to either underestimate or overestimate of SF-6D utility scores in our study. Third, we derived average HRQoL utility scores based on follow-up surveys 1, 3 and 6 months after release, and as such may have failed to capture variation in HRQoL over more than half of the follow-up time. If increased contact with health services in the intervention group improved HRQoL only after some time (e.g., by improving management of chronic conditions through improved engagement with primary care), this effect may not have been captured, and our results would thus underestimate the impact of the intervention on HRQoL during the study period. Although longitudinal studies with ex-prisoners and other vulnerable populations are both challenging and resource intensive, ${ }^{51}$ future studies should consider a longer period of follow-up if resources permit.

\section{CONCLUSION}

This study examined a complex policy and research question with a wide range of potential economic impacts. The findings of this study do not bring economic evidence to support the widespread adoption of the Passports intervention, although they also highlight the complexities of cost-effectiveness evaluation in this area. Given the limitations in our approach to modelling, further research on the potential cost-effectiveness of transitional interventions for people leaving prison is needed to inform evidence-based policy making.

\section{Author affiliations}

${ }^{1}$ Australian Centre for Health Services Innovation (AusHSI), Institute of Health and Biomedical Innovation, Queensland University of Technology, Brisbane, Queensland, Australia

${ }^{2}$ Melbourne School of Population and Global Health, University of Melbourne, Melbourne, Victoria, Australia

${ }^{3}$ Griffith Criminology Institute \& Menzies Health Institute Queensland, Griffith University, Brisbane, Queensland, Australia

${ }^{4}$ Mater Research Institute, University of Queensland, Brisbane, Queensland, Australia

${ }^{5}$ School of Public Health and Preventive Medicine, Monash University, Melbourne, Victoria, Australia

${ }^{6}$ Centre for Adolescent Health, Murdoch Childrens Research Institute, Melbourne, Victoria, Australia
Contributors NG and SAK conceptualised and received funding for the study. NG, SAK, QC and XJL led the development of methods used in the study. Data analysis was conducted by QC, XJL and KJS. All authors contributed to the writing of first draft and reviewing and editing of the manuscript. All authors approved the final submitted version of the manuscript.

Funding NG and SAK received funding from National Health and Medical Research Council (NHMRC). Grant number: 1060024. NHMRC website: https://www.nhmrc. gov.au/.

Disclaimer The funder had no role in study design, data analysis, decision to publish or preparation of the manuscript.

Competing interests None declared.

Patient consent Not required.

Ethics approval This study has received ethics approval from the University of Queensland Behavioural and Social Sciences ethical review committee, Queensland Health human research ethics committee and Australian Institute of Health and Welfare ethics committee. Data linkage to Medicare Benefits Schedule and Pharmaceutical Benefits Scheme was approved by the Commonwealth Department of Human Services.

Provenance and peer review Not commissioned; externally peer reviewed.

Data sharing statement Data are from the Passports Study and are the subject of multiple ethics and data custodian approvals. Access to the data is subject to amendments to these approvals. Parties interested in accessing the data should contact Stuart Kinner (s.kinner@unimelb.edu.au) in the first instance.

Open access This is an open access article distributed in accordance with the Creative Commons Attribution Non Commercial (CC BY-NC 4.0) license, which permits others to distribute, remix, adapt, build upon this work non-commercially, and license their derivative works on different terms, provided the original work is properly cited, appropriate credit is given, any changes made indicated, and the use is non-commercial. See: http://creativecommons.org/licenses/by-nc/4.0/.

\section{REFERENCES}

1. Australian Bureau of Statistic. 4517.0 - Prisoners in Australia. 2016 Canberra: Australian Bureau of Statistics 2016 http://www.abs. gov.au/AUSSTATS/abs@.nsf/Lookup/4517.0Main+Features12016? OpenDocument.

2. The health of Australia's prisoners 2015. Canberra: Australian Institute of Health and WelfareAlHW, 2015.

3. SCRGSP (Steering Committee for the Review of Government Service Provision). Report on Government Services 2016. vol. C. Justice, Canberra: Productivity Commission, 2016.

4. Rollings K. Counting the costs of crime in Australia: a 2005 update. Canberra: Australian Institute of Criminology, 2008.

5. Butler T, Belcher JM, Champion U, et al. The physical health status of young Australian offenders. Aust N Z J Public Health 2008;32:73-80.

6. Butler T, Andrews G, Allnutt S, et al. Mental disorders in Australian prisoners: a comparison with a community sample. Aust $N Z J$ Psychiatry 2006;40:272-6.

7. Butler T, Levy M, Dolan K, et al. Drug use and its correlates in an Australian prisoner population. Addict Res Theory 2003;11:89-101.

8. Kinner SA, Dietze PM, Gouillou M, et al. Prevalence and correlates of alcohol dependence in adult prisoners vary according to Indigenous status. Aust N Z J Public Health 2012;36:329-34.

9. Fazel S, Bains P, Doll H. Substance abuse and dependence in prisoners: a systematic review. Addiction 2006;101:181-91.

10. Kinner SA. Continuity of health impairment and substance misuse among adult prisoners in Queensland, Australia. Int J Prison Health 2006;2:101-13.

11. Kinner SA. The post-release experience of prisoners in Queensland. Trends \& Issues in Crime and Criminal Justice 2006;325:1-6.

12. Binswanger IA, Stern MF, Deyo RA, et al. Release from prison--a high risk of death for former inmates. N Engl J Med 2007;356:157-65.

13. Kinner SA, Andrews JY, Stoové M, et al. Counting the cost: Estimating the number of deaths among recently released prisoners in Australia, 2011:64.

14. Hobbs M, Krazlan K, Ridout S, et al. Mortality and morbidity in prisoners after release from prison in Western Australia 1995-2003: Canberra: Australian Institute of Criminology, 2006.

15. Andrews JY, Kinner SA. Understanding drug-related mortality in released prisoners: a review of national coronial records. BMC Public Health 2012;12:270. 
16. Rosen DL, Schoenbach VJ, Wohl DA. All-cause and cause-specific mortality among men released from state prison, 1980-2005. Am J Public Health 2008;98:2278-84.

17. Kariminia A, Butler TG, Corben SP, et al. Extreme cause-specific mortality in a cohort of adult prisoners - 1988 to 2002: a data-linkage study. Int J Epidemiol 2007;36:310-6.

18. Binswanger IA, Blatchford PJ, Forsyth S, et al. Incidence, timing and risk factors for death related to infectious disease after release from prison in the United States and Australia: a retrospective cohort study. Public Health Reports. In Press.

19. Dowden C, Brown SL. The role of substance abuse factors in predicting recidivism: a Meta-analysis. Psychology, Crime \& Law 2002;8:243-64.

20. Payne J. Recidivism in Australia: findings and future research Canberra: Australian institute of criminology, 2007

21. Wilson JA, Wood PB. Dissecting the relationship between mental illness and return to incarceration. J Crim Justice 2014;42:527-37.

22. Wolitski RJ. Relative efficacy of a multisession sexual risk-reduction intervention for young men released from prisons in 4 states. $\mathrm{Am} \mathrm{J}$ Public Health 2006;96:1854-61.

23. Friedmann PD, Green TC, Taxman FS, et al. Collaborative behavioral management among parolees: drug use, crime and re-arrest in the Step'n Out randomized trial. Addiction 2012;107:1099-108.

24. Wikoff N, Linhorst DM, Morani N. Recidivism among participants of a reentry program for prisoners released without supervision. Soc Work Res 2012;36:289-99.

25. Petersilia J. What works in prisoner reentry? reviewing and questioning the evidence. Federal Probation 2004;68:4-8.

26. Farrington DP, Welsh BC. Randomized experiments in criminology: what have we learned in the last two decades? J Exp Criminol 2005;1:9-38.

27. Wilson JA, Davis RC. Good intentions meet hard realities: an evaluation of the project greenlight reentry program*. Criminology \& Public Policy 2006;5:303-38.

28. Kinner SA, Lennox N, Williams GM, et al. Randomised controlled trial of a service brokerage intervention for ex-prisoners in Australia. Contemp Clin Trials 2013;36:198-206.

29. Kinner SA, van Dooren K, Boyle FM, et al. Development of an intervention to increase health service utilisation in ex-prisoners. Health Justice 2014;2:4.

30. Kinner SA, Alati R, Longo M, et al. Low-intensity case management increases contact with primary care in recently released prisoners: a single-blinded, multisite, randomised controlled trial. J Epidemiol Community Health 2016;70:683-8.

31. Tijms HC. Chapter 1. The Poisson Process and Related Processes. $A$ First Course in Stochastic Models: John Wiley and Sons, 2003.

32. Queensland Audit Office. Queensland Ambulance Service performance Report 17: 2013-2014. Brisbane: The State of Queensland, 2014

33. SCRGSP (Steering Committee for the Review of Government Service Provision). Report on Government Services 2015, vol. C, Justice. Canberra: Productivity Commission, 2015
34. National Hospital Costing Data Collection. Round 14 (2009-10) National Public Cost Weight Tables- version 6.0x and version 5.2 2012 http://www.R-project.org/..

35. Independent Hospital Pricing Authority. National Efficient Price Determination 2014, 2013.

36. Australian Bureau of Statistic. 6401.0 - Consumer Price Index, Australia, Dec 2015: TABLE 7. CPI: Group, Sub-group and Expenditure Class, Weighted Average of Eight Capital Cities. CANBERRA: Australian Bureau of Statistics, 2016.

37. Wang $\mathrm{P}, \mathrm{Fu} \mathrm{AZ}$, Wee $\mathrm{HL}$, et al. Predicting preference-based SF-6D index scores from the SF-8 health survey. Qual Life Res 2013;22:1675-83.

38. Harris $\mathrm{AH}$, Hill SR, Chin G, et al. The role of value for money in public insurance coverage decisions for drugs in Australia: a retrospective analysis 1994-2004. Med Decis Making 2008;28:713-22.

39. Shiroiwa T, Sung YK, Fukuda T, et al. International survey on willingness-to-pay (WTP) for one additional QALY gained: what is the threshold of cost effectiveness? Health Econ 2010;19:422-37.

40. Briggs $\mathrm{AH}$, Claxton K, Sculpher MJ. Making decision models probabilistic. Oxford University Press: Decision Modelling for Health Economic Evaluation, 2006.

41. Core Team R. R: A Language and Environment for Statistical Computing Vienna. Austria: R Foundation for Statistical Computing, 2017.

42. Young JT, Arnold-Reed D, Preen D, et al. Early primary care physician contact and health service utilisation in a large sample of recently released ex-prisoners in Australia: prospective cohort study. BMJ Open 2015;5:e008021.

43. Tudor Hart J. The inverse care law. The Lancet 1971;297:405-12.

44. Furler JS, Harris E, Chondros $\mathrm{P}$, et al. The inverse care law revisited: impact of disadvantaged location on accessing longer GP consultation times. Med J Aust 2002;177:80-3.

45. Wang EA, Hong CS, Shavit $S$, et al. Engaging individuals recently released from prison into primary care: a randomized trial. Am J Public Health 2012;102:e22-e29.

46. Miller WR, Rollnick S. Motivational Interviewing: Preparing People for Change. Second edition. New York: Guilford Press, 2002.

47. Thomas EG, Spittal MJ, Heffernan EB, et al. Trajectories of psychological distress after prison release: implications for mental health service need in ex-prisoners. Psychol Med 2016;46:611-21.

48. Kind P, Lafata JE, Matuszewski K, et al. The use of QALYs in clinical and patient decision-making: issues and prospects. Value Health 2009;12(Suppl 1):S27-S30.

49. Drummond MF, Sculpher MJ, Claxton K, et al. Economic evaluation using decision analytic modelling. OUP Oxford: Methods for the Economic Evaluation of Health Care Programmes, 2015.

50. Brazier JE, Roberts J. The estimation of a preference-based measure of health from the SF-12. Med Care 2004;42:851-9.

51. David MC, Alati R, Ware RS, et al. Attrition in a longitudinal study with hard-to-reach participants was reduced by ongoing contact. $J$ Clin Epidemiol 2013;66:575-81. 